\title{
Injuries Caused By Borrowed Dentures: Antithesis to Elderly Abuse - A Forewarning
}

\author{
Authors \\ Dr Munawwar Husain ${ }^{1}$, Dr Mohammad Asrarul Haque ${ }^{2}$, Dr Mohammad Mojahid \\ Anwar $^{3}$, Dr Faiz Ahmad ${ }^{4}$, Dr Mohammad Adil ${ }^{5}$, Dr Afzal Ahmad ${ }^{6}$, \\ Dr Jawed Ahmad Usmani ${ }^{7}$ \\ ${ }^{1}$ MBBS, MD, DNB, MNAMS, Dip in Criminology \& Criminal Administration, Professor \\ ${ }^{2}$ MBBS, MD, Senior Resident \\ ${ }^{3}$ MBBS, D. Ophth, JR-III \\ ${ }^{4} \mathrm{MBBS}, \mathrm{JR}-\mathrm{II}$ \\ ${ }^{5}$ MBBS, MD (Dermatology), Senior Resident, Department of Dermatology \\ ${ }^{6}$ BDS, Junior Resident, Dr Z.A Dental College, AMU, Aligarh 202002 \\ ${ }^{7}$ MBBS, MD (Path), MD (For Med), Dip in Criminology \& Criminal Administration, \\ Professor \& Chairman, Department of Forensic Medicine, J N Medical College, AMU, Aligarh 202002 \\ Corresponding Author \\ Dr Faiz Ahmad \\ Email: faizahmad61@gmail.com, Mobile No. +917417593173
}

\begin{abstract}
During the last few decades there had been an exponential rise in cases involving elderly abuse. The authors believe it to be a national shame. However, at the same time the authors advise for an exercise of caution. All cases may not be of abuse. This paper deals with injuries sustained during innocent activity and yet strongly mimic those of elderly abuse. Oral cavity has been selected for the study in which focus is maintained on injuries caused by artificial dentures.
\end{abstract}

Keywords: Borrowed dentures, elderly abuse, Oral injuries,

\section{Background}

It is only in the last two to three decades that abuse of the elderly has caught the attention of the public and the medical establishment. The first report of the abuse of the elderly in the literature was Burston's letter to the British Medical Journal on "granny-battering" 1. This was followed closely by Butler's book, "Why Survive? Growing old in America" 2 . Now considerable interest has kindled on this issue and some form of law has been enacted in many states in USA ${ }^{3}$.

Conservative estimate is that $10 \%$ of the elders suffer abuse in some form and $2 \%$ with physical abuse 4. Elderly abuse may take many forms, categorized in to (i) physical abuse (ii) mental, emotional or psychological abuse (iii) neglect and (iv) economic abuse, such as theft or misuse of the elder's asset ${ }^{1}$. 
A broad definition of elder abuse or mistreatment is any adverse act or omission against an elderly patient ${ }^{6}$.

\section{American Medical Association Definition ${ }^{7}$}

Physical abuse: Acts of violence that may result in pain, injury, impairment or disease

Physical neglect: Failure of the care giver to provide the goods or services that are necessary for optimal functioning; avoidance of the older person

Psychological abuse: Conduct that causes mental anguish in an older person

Psychological neglect: Failure to provide a dependent elderly individual with social stimulation

Financial or material abuse: Misuse of the elderly person's income or resources for the financial or personal gain of a care taker or advisor

Financial or material neglect: Failure to use available funds and resources necessary to sustain or restore the health and well being of an older person

Violation of human rights: Care taker or provider ignoring the older person's rights and capability to make decisions for himself or herself Intent to cause harm is difficult to evaluate and even more difficult to prove. It is probably beyond the scope of the clinician to delve deeply in to the issue of intent 8 .

There has been tremendous pressure on land and housing particularly in metropolitan as well as Bclass cities. The natural corollary is that each inch of space is fought for. Within the family itself priorities change. Older persons, especially not having the source of income are gradually shunted out from the room to the verandah and then to the central door. It is only a matter of time before the door is opened and the individual is shown the door.

\section{BYOT: Bring Your Own Teeth ${ }^{9}$}

Elderly persons who live in old-age homes or other institutions are taken care of by the staff of course payment is generally made by the kith and kin. However, it is seen that despite all the checks and balances meant to ensure that they are being taken care of properly some lapses are evident. These manifest in the form of unhygienic proliferation of their activities. Few older persons are indigenous in nature and form small groups in which they partake in all activities - a smart way to kill time and air their grievances directed against their own relatives and institutional staff. One form of strong camaraderie and friendship bond is that they tend to share all their belongings however meager these may be. Sharing of dentures among the elderly has been observed quite often, in fact much oftener than we tended to believe. We call them sharing of dentures. Because the dentures are ill-fitting these tend to cause injuries in multiple fashions depending on the portion of denture that does not fit. Ironically the inmates of old age homes are looked upon with compassion and pity. Therefore, in all possibility any injury would be attributed to carelessness and neglect by the old age home staff. This may not be the case always.

Hilarious though it may seems, elderly people have a way to communicate in a lighter note and at the same time pass on the message: BYOT. Do not ask for my dentures. This is what they want to say. Bring your own one if you want to enjoy the meal and remain safe from injury.

We take a look at four typical injuries which are caused by ill-fitting dentures in edentulous persons and caution doctors against misinterpreting them to be the result of elderly abuse and neglect. 


\section{Injuries that need a second look}

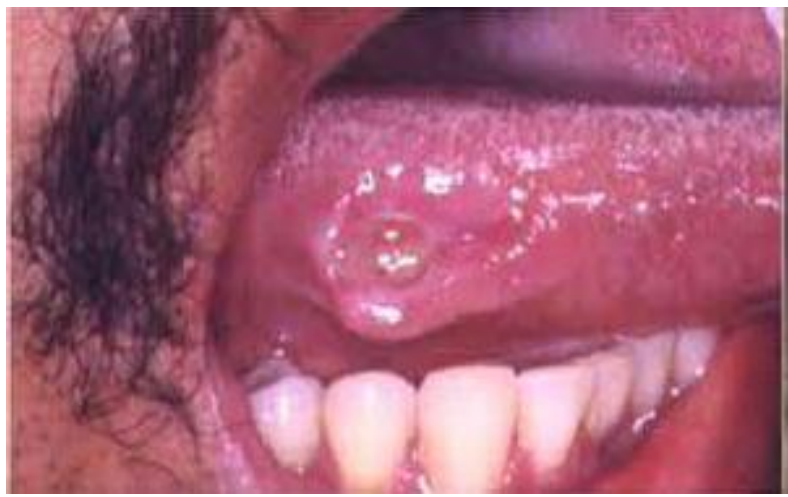

Fig: 1Traumatic Ulcer on Tongue

Accidental biting during mastication, sharp pointy food may cause acute traumatic ulceration. Chronic trauma from sharp edges of teeth, restorations and appliances particularly ill-fitting dentures may cause chronic ulcers. Chronic traumatic ulcers ar commonly found on the mucosa that is subjected to trauma from dentition such as buccal mucosa, lateral border of the tongue or lips. Lesions on other areas including muco-buccal folds and gingivae are associated with other sources of irritation such as trauma from tooth brush or food ${ }^{10}$.

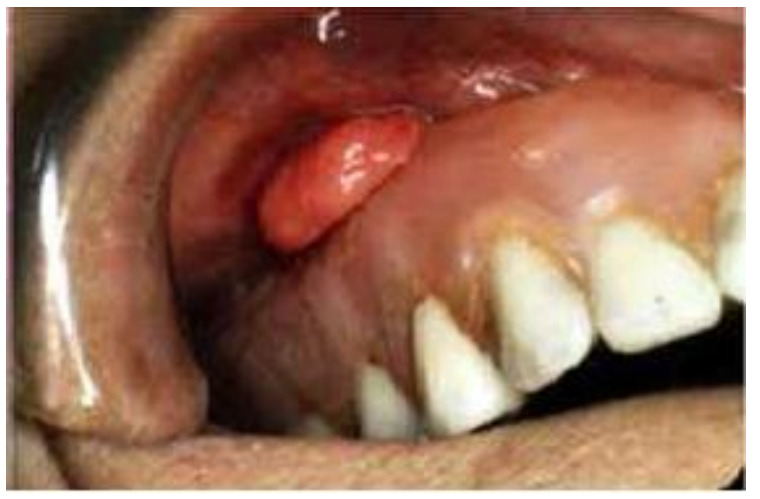

Fig: 2 Inflammatory Fibrous Hyperplasia/ Denture Injury Tumour

Tumour like hyperplasia of fibrous connective tissue that develops in association with the flange of an ill fitting denture.

Presents as single or multiple folds of tissue in the alveolar mucosa; usually presents as two folds with denture flanges in between. The size varies from $<1 \mathrm{~cm}$ to large lesions involving the entire length of vestibule. Appears as firm, fibrous tissue with variable ulcerations and erythema. Most common location is facial aspect of alveolar ridges; anterior portions of jaws and older adults with female predilection ${ }^{11}$.

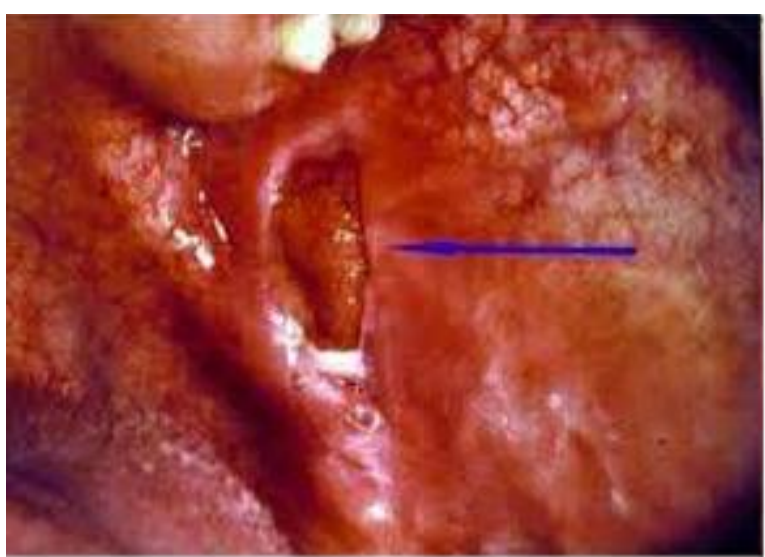

Fig 3 Traumatic Ulceration

Traumatic injuries involving the oral cavity may typically lead to the formation of surface ulcerations. The injuries may result from events such as accidentally biting oneself while talking, sleeping, or secondary to mastication. Other forms of mechanical trauma, as well as chemical, electrical, or thermal insults, may also be involved. In addition, fractured, carious, malposed, or malformed teeth, as well as the premature eruption of teeth, can contribute to the formation of surface ulcerations. Poorly maintained and ill-fitting dental prosthetic appliances may also cause trauma ${ }^{12}$.

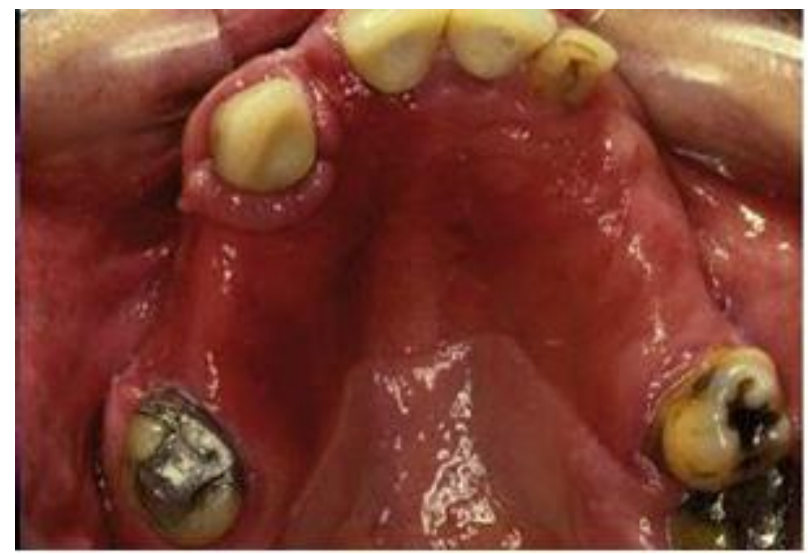

Fig 4 Denture-Related Stomatitis

The oral mucosa of the denture-bearing area is erythematous, oedematous and hyperplastic.

Candida albicans was recovered from the fitting surface of the denture on the midline dorsal tongue. 
Usually symptomless, epithelial hyperplasia with neutrophils in the para keratin layer ${ }^{13}$.

\section{Conclusion}

This paper has tended to highlight those injuries, without bias, which may be interpreted to have been caused by physical abuse of the elderly persons. Detailed history and personal preferences must be noted so that differentiation becomes easy. Institutionalized existence no matter how comfortable it may be always carry seclusion, frustration and disappointment. Even sharing a denture is a luxury for those who do not afford to have one. Therefore, before diagnosing it to be the product of abuse the oral cavity injury should be explored fully. Interviewing the elderly would establish the fact that the person was in the habit of borrowing dentures for personal use.

These dentures would necessarily be ill fitting. Caution must be observed as a matter of practice.

\section{References}

1. Burston GR. Granny-battering. Br Med J., 1975; 5: 592.

2. Butler RN. Why survive? Growing old in America. Harper \& Row, New York, 1975.

3. Wolf RS. Elder abuse: ten years later. J Am. Geriatric Soc., 1988; 36: 758.

4. American Medical Council on Scientific affairs Report: Elder abuse and neglect. J Am Med Assoc., 1987; 257: 966.

5. Burston GR. Granny-battering. Br Med J., 1975; 5: 592.

6. Kosberg JI, Nahmiash D. Characteristics of victims and perpetrators and milieus of abuse and neglect. In: Baumhover LA, Beall SC, ed. Abuse, neglect and exploitation of older persons: strategies for assessment and intervention. Baltimore, MD: Health Professions Press, 1996: 3149.

7. Adapted from Aravami SC, Adelman RD Breckman $\mathrm{R}$, et al. diagnostic and treatment guidelines on elder abuse.
Chicago: American Medical Association, 1992

8. Fulmer TT, Gould ES. Assessing neglect. In: In: Baumhover LA, Beall SC, ed. Abuse, neglect and exploitation of older persons: strategies for assessment and intervention.Baltimore, MD: Health Professions Press, 1996: 89-103.

9. http://burningjournal.activeboard.com/t419 15113/ger

Accessed on 29/9/2015.

10. http://pocketdentistry.com/11-mucosaldiseases/

Accessed on 07/10/2015

11. https://www.studyblue.com/notes/note/n/o ral-pathology-/deck/8823448

Accessed on 07/10/ 2015

12. https://www.studyblue.com/notes/note/n/p hysical-and-chemical-injuries/deck/5481874

Accessed on 07/10/2015

13. https://www.studyblue.com/notes/note/n/o ral-pathology/deck/2758136

Accessed on 07/10/2015 